\title{
COPIM
}

\section{COPIM's response to the UKRI OA Consultation}

\section{Janneke Adema}

Published on: Jun 05, 2020

DOI: 10.21428/785a6451.9e58d1d8

License: Creative Commons Attribution 4.0 International License (CC-BY 4.0). 
On behalf of the COPIM project we submitted our response to the UKRI Open Access Review last week. Please find our response underneath. Note that individual members of and partners within the COPIM consortium have also submitted a response, which might differ from this collective response.

\section{Section B: Monographs, Book Chapters and Edited Collections}

Q33. To what extent do you agree or disagree that the types of monograph, book chapter and edited collection defined as in-scope and out-of-scope of UKRI's proposed OA policy (see paragraphs $96-98$ of the consultation document) are clear?

Strongly agree / Agree / Neither agree nor disagree / Disagree / Strongly disagree / Don't know / No opinion.

If you disagree, please explain your view (2,000 characters maximum, approximately 300 words).

With respect to trade books we feel the criteria in UKRI's proposed OA policy are too broad and vague, providing an easy way out of the OA requirement for publishers and authors. What would qualify as a 'higher print run' or a change in the 'price point'? What about fields such as media studies or history, where monographs (e.g. on Dr Who or WWII) do frequently appeal to a broader audience and the price point is often by default lower than in more specialised academic fields or topics? There is a lot of crossover between monographs and trade books, and the fact that this crossover exists means that what qualifies as a trade book should be either defined more strictly or - and this would be our preferred option - any output that receives UKRI funding, whether it is a specialised monograph or a trade book, should be made available in open access, as there is no evidence that this would harm sales and might even promote the dissemination of the book.

Q34. Should the following outputs be in-scope of UKRl's OA policy when based on UKRI-funded doctoral research?

a. Academic monographs Yes / No / Don't know / No opinion

b. Book chapters Yes / No / Don't know / No opinion

c. Edited collections Yes / No / Don't know / No opinion

Please explain your view (1,350 characters maximum, approximately 200 words). 
We feel that they should, yes. But arrangements need to be put in place to ensure that researchers are able to publish their first book or deposit it in an institutional repository if they change institutions or leave their current university. Many $\mathrm{PhD}$ students already publish their research-in-progress before their thesis is finalised (specifically outputs b and c). But at the moment $\mathrm{PhD}$ students do not, for the most part, have access to institutional grants to publish on an OA basis, for example. Provisions need to be available for them to publish OA or deposit their outputs in a repository.

Q35. To what extent do you agree or disagree that UKRI's OA policy should include an exception for in-scope monographs, book chapters and edited collections where the only suitable publisher in the field does not have an OA programme?

Strongly agree / Agree / Neither agree nor disagree / Disagree / Strongly disagree / Don't know / No opinion.

Please explain and, where possible, evidence your view (1,350 characters maximum, approximately 200 words).

We feel there are enough publishers that publish widely in the humanities and critical theory who either have an OA programme or publish fully in OA, such as Open Book Publishers, Punctum Books, Mattering Press, meson press, and Open Humanities Press, in addition to the various university presses with broad lists and series. (For more examples, look among the 60+ members of the Radical Open Access Collective: http://radicaloa.disruptivemedia.org.uk).

The drawback of such an 'exception' clause is that it might again provide a way out of publishing OA for both authors and publishers: they could easily argue that they are a 'specialised press' offering an unique service; or that a book can only be published by such a 'specialised press'. Who would assess what is 'the only suitable publisher in the field', and what would the criteria for this be?

Q36. Are there any other considerations that the UK HE funding bodies should take into account when defining academic monographs, book chapters and edited collections in-scope of the OA policy for the REF-after-REF 2021?

Yes / No / Don't know / No opinion.

If yes, please expand (2,000 characters maximum, approximately 300 words). Please see paragraphs 29-31 of the consultation document before answering this question. 
Digital works and practice-based works that would fit neither a definition of 'long-form work' (for example, see the showcase of works produced on the Scalar platform here), or works that fall in between research article and monograph formats. For example, many presses are now publishing short or mid-length books/monographs, such as Minnesota University Press's Forerunners: Ideas First $\underline{\text { series, }}$ or the Media: Art: Write: Now series from Open Humanities Press, or MIT Press's Untimely_ Mediations.

Q37. Regarding monographs in-scope of UKRl's proposed OA policy, which statement best reflects your view on the maximum embargo requirement of 12 months?

a. 12 months is appropriate

b. A longer embargo period should be allowed

c. A shorter embargo period should be required

d. Different maximum embargo periods should be required for different discipline areas

e. Don't know

f. No opinion

Please explain and, where possible, evidence your answer. If you answered $b, c$ or $d$ please also state what you consider to be (an) appropriate embargo period(s) (1,350 characters maximum, approximately 200 words).

We consider a zero embargo period appropriate. Where it concerns scholarly books, research by_ Ronald Snijder and others shows no decline in sales or income for publishers once they release their scholarly books on an OA basis. The open availability does however lead to more discovery and online consultation, meaning that it might actually lead to more 'impact' for scholarly books. For more see:

- Ronald Snijder, “The Deliverance of Open Access Books: Examining Usage and Dissemination” (Leiden University, 2019).

- Eelco Ferwerda, Ronald Snijder, and Janneke Adema, "OAPEN-NL. A Project Exploring Oppen Access Monograph Publishing in the Netherlands: Final Report" (The Hague: OAPEN Foundation, October 2013).

- Eelco Ferwerda, Ronald Snijder, Brigitte Arpagaus, Regula Graf, Daniel Krämer, Eva Moser, “The impact of open access on scientific monographs in Switzerland. A project conducted by the Swiss 
National Science Foundation (SNSF)" (OAPEN-CH).

- Ronald Snijder, "The profits of free books: an experiment to measure the impact of open access publishing," Learned Publishing, 23: 293-301.

Q38. Regarding book chapters in-scope of UKRl's proposed OA policy, which statement best reflects your view on the maximum embargo requirement of 12 months?

a. 12 months is appropriate

b. A longer maximum embargo period should be allowed

c. A shorter maximum embargo period should be required

d. Different maximum embargo periods should be required for different discipline areas

e. Don't know

f. No opinion

Please explain and, where possible, evidence your answer. If you answered $b, c$ or $d$ please also state what you consider to be (an) appropriate embargo period(s) (1,350 characters maximum, approximately 200 words).

With single book chapters especially, we see no reason why there should not be a zero embargo period. As noted in our answer to Q37, research by Ronald Snijder (https://doi.org/10.1087/20100403) shows no decline in sales or income for publishers once they release their scholarly books on an open access basis. If making the whole book available OA doesn't affect income generation, then it is no surprise that there is no evidence that making a single chapter from a book, or even a few chapters, openly available on an open access basis impacts on the sales of edited collections either.

Q39. Regarding edited collections in-scope of UKRl's proposed OA policy, which statement best reflects your view on the maximum embargo requirement of 12 months?

a. 12 months is appropriate

b. A longer embargo period should be allowed 


\section{c. A shorter embargo period should be required}

d. Different maximum embargo periods should be required for different discipline areas

e. Don't know

f. No opinion

Please explain and, where possible, evidence your answer. If you answered $b, c$ or $d$ please also state what you consider to be (an) appropriate embargo period(s) (1,350 characters maximum, approximately 200 words).

See our answer to Q37 and Q38.

Q40. Do you have any specific views and/or evidence regarding different funding implications of publishing monographs, book chapters or edited collections with no embargo, a 12-month embargo or any longer embargo period?

Yes/No.

If yes, please expand (2,000 characters maximum, approximately 300 words). Please note that funding is further considered under paragraph 110 of the consultation document (question 53).

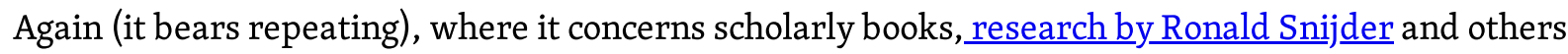
shows no decline in sales or income for publishers once they release their scholarly books in open access. The open availability does however lead to more discovery and online consultation, meaning that it actually might lead to more 'impact' for scholarly books. For more see:

- Ronald Snijder, "The Deliverance of Open Access Books: Examining Usage and Dissemination" (Leiden University, 2019).

- Eelco Ferwerda, Ronald Snijder, and Janneke Adema, “OAPEN-NL. A Project Exploring Open Access Monograph Publishing in the Netherlands: Final Report" (The Hague: OAPEN Foundation, October 2013).

- Eelco Ferwerda, Ronald Snijder, Brigitte Arpagaus, Regula Graf, Daniel Krämer, Eva Moser, “The impact of open access on scientific monographs in Switzerland. A project conducted by the Swiss National Science Foundation (SNSF)" (OAPEN-CH) doi: 10.5281/zenodo.1220607

- Ronald Snijder, “The profits of free books: an experiment to measure the impact of open access publishing," Learned Publishing, 23:293-301, doi: $\underline{10.1087 / 20100403}$ 
- Rachel Pells, "Open access: "no evidence" that zero embargo periods harm publishers", Times Higher Education, 23 April 2019.

Q41. To what extent do you agree that self-archiving the post-peer-review author's accepted manuscript should meet the policy requirement?

Strongly agree / Agree / Neither agree nor disagree / Disagree / Strongly disagree / Don't know / No opinion.

Please explain and your view (1,350 characters maximum, approximately 200 words).

We feel strongly that a green open access option should be included, mainly because of the high prices of BPCs. These will make publishing OA on a gold BPC basis unachievable for most researchers and their institutions. The support of UKRI for infrastructures such as institutional repositories or a central deposit service (i.e. via an organisation such as DOAB) that enables such a green OA option would be essential. (See our answer to Q34 for more.) Please also see our response in question 42 below on some of the additional considerations UKRI will need to address in order to make this workable.

Q42. Regarding monographs, book chapters and edited collections, are there any additional considerations relating to $O A$ routes, deposit requirements and delayed $O A$ that the UK HE funding bodies should take into account when developing the OA policy for the REF - after-REF 2021?

Yes / No / Don't know / No opinion.

If yes, please expand (2,650 characters maximum, approximately 400 words). Please see paragraphs 29-31 of the consultation document before answering this question.

Although we feel that green OA should be an acceptable route to compliance for books, many issues do remain with how this may work. UKRI should take action to specifically define what is meant by, for example, an 'accepted manuscript', bearing in mind that manuscripts are accepted by publishers at varying stages in the editorial process. UKRI should therefore stipulate that the entire manuscript should be made available, rather than just a sample chapter.

There is also a risk that green OA relegates open access to second-tier status within publishing. There are many enhancements made to the content of monographs after acceptance, including important questions of design and presentation. These considerations are all the more important with respect to 
enhanced digital monographs with rich media, post-peer-reviewed content, and other experimental forms of presentation. In this instance, an accepted manuscript will be of limited value without the accompanying multimedia aids. UKRI should be careful to stipulate what green OA should look like for these kinds of monographs because such experimentation should be supported rather than discouraged.

There are also considerations around marketing of the green OA version: Is the publisher obligated to make readers aware that a free version exists in a repository, or are they allowed to simply upload it and rely on readers to find this out for themselves? Again, this would relegate the green OA version to second-tier status and would reduce open access to a box-ticking exercise. UKRI should stipulate how visible they expect green $O A$ versions to be.

Q43. To what extent do you agree or disagree with CC BY-ND being the minimum licencing requirement for monographs, book chapters and edited collections inscope of UKRI's proposed OA policy?

Strongly agree / Agree / Neither agree nor disagree / Disagree / Don't know / No opinion.

Please explain and, where possible, evidence your view (1,350 characters maximum, approximately 200 words).

There are issues with CC BY-ND becoming the standard in this situation, as it would risk excluding reuse and remix of content, which lies at the heart of various groundbreaking OA experimental publishing projects such as Open Humanities Press's Living Books about Life, its Photomediations: An Open Book, as well as punctum's Making The Geological Now.

Similarly, we are keen to acknowledge the importance of the CC BY-NC license, given the example of the Knowledge Unlatched 'Open Research Library' (ORL) which in 2016 transitioned from a Community Interest Corporation (CIC) registered in the UK, to a for-profit ( $\mathrm{GmbH}$ ) company registered in Germany (see https://blog.scholarled.org/open-research-libraryL; https://punctumbooks.pubpub.org/pub/creative-commons-by-nc-licensing-open-access).

The ORL is a prime example of 'openwrapping' and 'openwashing' (monetising services, engagement, and infrastructural support around openly licensed content). At the same time there should be scope for the use of alternative CopyLeft or CopyFarLeft licenses (https://wiki.p2pfoundation.net/Copyfarleft) that do not easily translate to CC BY-ND. 
Q44. To what extent do you agree or disagree that UKRI's OA policy should include an exception for in-scope monographs, book chapters and edited collections requiring significant reuse of third-party materials?

Strongly agree / Agree / Neither agree nor disagree / Disagree / Strongly disagree / Don't know / No opinion.

Please explain your view (1,350 characters maximum, approximately 200 words). Questions $45-46$ concern how 'significant reuse' may be defined.

In brief, the question is again, how would 'significant reuse of third-party materials' be defined, and who would decide what was significant and what was not? How can this be done so as to avoid providing an easy way out of the OA requirement for publishers and authors? Given the problems with existing licensing conditions related to images, for example, we feel this might be a reasonable compromise for now, but we would urge museums and heritage institutions to embrace open licensing of third party materials. For example, images should be tagged with a relevant Creative Commons license, or marked as being 'in the public domain' or having 'no known copyright restrictions' (the latter being a designation adopted on Flickr: The Commons, when cultural institutions have reasonably concluded that an image is free of copyright restrictions). More information on the relevant licenses is available here: http://opendefinition.org/licenses/.

We would like to highlight that there are various open source repositories for images too. See, for example, CCSearch;Europeana; Flickr: The Commons; and Wikimedia Commons.

Q45. To what extent do you agree or disagree that if an image (or other material) were not available for reuse and no other image were suitable, it would be appropriate to redact the image (or material), with a short description and a link to the original?

Strongly agree / Agree / Neither agree nor disagree / Disagree / Strongly disagree / Don't know / No opinion.

Please explain your view (1,350 characters maximum, approximately 200 words).

We feel this would be appropriate for an online OA version.

Our colleagues at Open Book Publishers have done this with two of their books by Kathryn Rudy, Piety_ in Pieces (2016) and Image, Knife, and Gluepot (2019) with great success. In both, permanent links were given to images that were freely available on the web, rather than paying to reproduce them in the books (in addition to the many images that were reproduced in the books). This practice was part of 
Rudy's argument, which called attention to the difficulty of manuscript study when institutions have restrictive policies around image reproduction. It was commended in reviews (e.g. see Elizabeth Savage, The Library, 19:2 (2018), 230-31).

Rudy used funding to make many more images freely available online and then linked to them, rather than using the money to publish them. She thus made these resources freely available online for others. This is a practice that might be taken up more widely.

Rudy's books are highly valued by readers. $\underline{\text { Piety in Pieces has been accessed over } 10,000}$ times and Image, Knife and Gluepot has been accessed over 2, 000 times. They have been extremely well reviewed and Piety in Pieces won the 2017 Choice Review's Outstanding Academic Title.

Open Book Publishers have since taken this approach with other books.

Q46. Do you have a view on how UKRI should define 'significant use of third-party materials' if it includes a relevant exception in its policy?

Yes / No / Don't know / No opinion.

If yes, please expand (2,000 characters maximum, approximately 300 words).

We think better guidance from UKRI here would be extremely important in order to establish exactly what is meant by 'significant' use, to ensure any minimal third-party materials reuse does not lead to an exemption of the policy.

Q47. Do you have any other comments relating to licensing requirements and/or the use of third-party materials, in relation to UKRl's proposed OA policy for academic monographs, book chapters and edited collections?

Yes / No.

If yes, please expand (1,350 characters maximum, approximately 200 words)

Echoing Open Book Publishers.

UKRI has an opportunity to take a lead in growing open image repositories. This OA policy demonstrates that Open Access to research has government support. UKRI is therefore uniquely positioned to have influential conversations with national institutions-our museums, libraries, galleries-about openly licencing the material in their collections for the benefit of academic research. 
UKRI could also collaborate with other funders, e.g. Wellcome Trust and Coalition S, towards the same goal. Access to third-party material is an international problem-there should be collective solutions and UKRI could help to bring them about. This data from OpenGLAM demonstrates the possibilities.

The other area is fair practice. Legal precedents support the argument that the 'quotation exception' to copyright infringement can apply to any media, as long as the 'quotation' is made with the intention of 'entering into a dialogue' with the relevant material. Cover images or decoration would be out of scope, but anything crucial to the argument (we might call it 'significant use') would fall within it. Fair practice has been limited by cautious publisher behaviour. UKRI could help to support change here.

Q48. Regarding monographs, book chapters and edited collections, are there any additional considerations relating to licensing requirements and/or third-party materials that you think that the UK HE funding bodies should take into account when developing the OA policy for the REF - after-REF 2021?

Yes / No / Don't know / No opinion.

If yes, please expand (2,650 characters maximum, approximately 400 words). Please refer to paragraphs 29-31 of the consultation document before

answering this question.

See our answers to Q44, Q45 and Q46.

Q49. Which statement best reflects your views on whether UKRI's OA policy should require copyright and/or rights retention for in-scope monographs, book chapters and edited collections?

a. UKRI should require an author or their institution to retain copyright and not exclusively transfer this to a publisher

b. UKRI should require an author or their institution to retain specific reuse rights, including rights to deposit the author's accepted manuscript in a repository in line with the deposit and licensing requirements of UKRI's OA policy

c. UKRI should require an author or their institution to retain copyright AND specific reuse rights, including rights to deposit the author's accepted manuscript in a repository in line with the deposit and licensing requirements of UKRI's OA policy 
d. UKRI's OA policy should not have a requirement for copyright or rights retention

e. Don't know

f. No opinion

Please explain and, where possible, evidence your answer.

If you selected answer b or c, please state what reuse rights you think UKRI's OA policy should require to be retained (2,000 characters maximum, approximately 300 words).

It is not necessary to repeat here, in full, the information provided in response to Q12.

Please note that views are not sought on whether institutions should hold the copyright to work produced by their employees as this is subject to Section 11 of the Copyright, Designs and Patents Act 1988 and institutional copyright policies.

Retaining copyright is one thing, but we feel there are also issues with publishers' usage of 'Exclusive License to Publish' licenses, in which publishers basically take all the distribution/publishing rights and allow the author to keep copyright in name only. This is incompatible with CC BY licenses.

Q50. Regarding the timing of implementation of UKRI's OA policy for monographs, book chapters and edited collections, which statement best reflects your view?

a. The policy should apply from 1 January 2024

b. The policy should apply earlier than 1 January 2024

c. The policy should apply later than 1 January 2024

d. Don't know

e. No opinion

Please explain and, where possible, evidence your answer. If you selected b or c, please also state what you consider to be a feasible implementation date (2,000 characters maximum, approximately 300 words).

As UKRI has already indicated in 2016 that books would be part of the next REF (and it was recommended as part of the Finch report already in 2012), we feel the start date should be in line with the start date of the next REF. However, exceptions could then be made for monographs for which the author signed a contract before that date or which are currently under contract. 
Open access book publishing has become increasingly mainstream over the last decade. Most of the large commercial publishers now have an open access book programme and many smaller presses such as those in the ScholarLed collective, as well as those in the Radical Open Access Collective with a book programme, have already been publishing books very succesfully in open access for several years. In addition to that the COPIM project is due to finish late 2022, and we will be putting in place the infrastructure and knowledge to assist smaller publishers to flip to OA.

Q51. In order to support authors and institutions with policy implementation UKRI will consider whether advice and guidance can be provided. Do you have any suggestions regarding the type of advice and guidance that might be helpful?

\section{Yes/ No}

If yes, please expand (2,000 characters maximum, approximately 300 words).

There is still a great deal of misinformation and misunderstanding about open access by humanities researchers, particularly the extent to which it poses a threat to their ways of working. At the same time many discussions around open access focus on funders' mandates and compliance, which can rub researchers the wrong way. We recommend UKRI take steps to engage with researchers directly to show why open access is beneficial (in terms of access, reuse, impact, and engagement) perhaps using case studies of the presses associated with COPIM, ScholarLed or the Radical Open Access Collective.

It would be good if the guidance could provide more information about what an author's accepted monograph is; When should the author's accepted monograph be deposited (the final accepted draft could be two years after "acceptance")?; what metadata standards would Institutional Repositories need to adopt to have deposited books (and what systems would they be expected to interact with e.g. $\mathrm{DOAB}$ ).

Q52. Regarding monographs, book chapters and edited collections, are there any other considerations that UKRI and the UK HE funding bodies need to take into account when considering the interplay between the REF-after-REF 2021 OA?

Yes / No / Don't know / No opinion.

If yes, please expand (2,650 characters maximum, approximately 400 words).

See our answers to the questions above. 
Q53. Do you have any views regarding funding levels, mechanisms and eligible costs to inform UKRI's considerations about the provision of funding for OA monographs, book chapters and edited collections in - scope of its proposed policy?

Yes / No.

If yes, please expand (2,650 characters maximum, approximately 400 words).

For more information on the sustainability of APCs see: Martin Paul Eve, Kitty Inglis, David Prosser, Lara Speicher, and Graham Stone, 'Cost Estimates of an Open Access Mandate for Monographs in the UK's Third Research Excellence Framework', Insights: The UKSG Journal, 30.3 (2017). doi: 10.1629/uksg. .392

Moving to a BPC-dependent publishing model would require substantial additional investment (Eve et al. 2017); BPCs are an inequitable and unsustainable way to fund OA. Although green OA does enable discoverability, a green option for books is not always readily available in the same way as it is for journals (due to copyright restrictions).

Also see Barnes, Lucy, and Rupert Gatti (28 May 2020). 'The Cost of Open Access Books: A Publisher Writes'. Open Book Publishers Blog.

As OA book publishing is becoming increasingly dependent on infrastructures provided by a small number of commercial platforms - a notorious example is (the openwashing of) Knowledge Unlatched, whose infrastructure for consortial funding is closed-source, defaults to the signing of exclusivity agreements by partners, and profits from its position as mediator between publishers and libraries. This leads to lock-in and poor competitive practices. Consequently, there is a need to provide further support for infrastructural projects such as COPIM and DOAB, in order to:

- Develop consortial, institutional, and other funding systems - which is of course what the COPIM consortium is doing-that will:

1) serve as important, hybrid, community-led revenue models for OA book publishers;

2) support the establishment of more community-owned and governed infrastructures; and

3) promote publisher-librarian partnerships around OA book publishing.

- Showcase alternative (non-BPC) business models that incorporate infrastructural innovations and/or cost-reductions through streamlined operating processes, production workflows and economic efficiencies - which would benefit all scales of publishing initiatives.

- Develop and pilot appropriate business models: the Crossick report (HEFCE) indicated that a new environment for OA books will need a variety of business models. Existing models face a series of practical and ethical challenges, including the tendency to (as we describe above) become overly 
reliant on Book Processing Charges (BPCs), which are potentially unsustainable (Eve et al. 2017) and worsen existing inequities in access to the means of publishing

Support for general IR type infrastructure is also crucial, including for a monograph version to add to the Sherpa suite, and support for open source software development (e.g. DSpace, E-prints etc.)

Q54. To support the implementation of UKRl's OA policy, are there any actions (including funding) that you think UKRI and/or other stakeholders should take to maintain and/or develop existing or new infrastructure services for OA monographs, book chapters and edited collections?

Yes / No / Don't know / No opinion.

If yes, please state what these are and, where relevant, explain why UKRI should provide support (2,650 characters maximum, approximately 400 words).

We think this is crucial. OA for books has not yet been widely adopted, even though books remain a very important publishing option for scholars in HSS disciplines (OAPEN-UK 2014). This means that the general public see a poor return on public investment in these fields, despite the high quality of much of the research undertaken and published. This is because the dominant systems, workflows, and infrastructures for the funding, production, dissemination, discovery, reuse, and archiving of scholarly books have been designed primarily with large, commercial, non-OA publishers in mind. This makes them fundamentally inappropriate for use by not-for-profit and/or OA book publishers. Furthermore, they are often inaccessible to them (e.g. due to high fees and licensing issues).

Building open-source, community-led infrastructures and workflows is the best way forward to address the hurdles OA books face: to achieve equity across different types of presses; and to ensure a diverse publishing ecology for OA books (Adema \& Stone 2017). The most important challenge facing OA books at the moment is that, despite clear signals from funders of an intention to mandate OA monographs, little demonstrable progress has been made towards actually meeting this goal. There is, however, a clear rationale for funders to play a leading role in promoting such activity given the proposed policy commitments.

The COPIM project is of course a valuable source of expertise that UKRI could consult, but, echoing the response from our colleagues at Open Book Publishers, there are a number of other organisations with whom UKRI might liaise to explore the development of infrastructure in fruitful ways, such as $\underline{\text { SCOSS }}$ and Invest in Open Infrastructure as well as initiatives like OPERAS-P. 
SCOSS aims to facilitate the security and sustainability of a global network of community-governed infrastructure projects, while Invest in Open Infrastructure is making the case for higher-education institutions to help support the systems that disseminate the research they produce, in ways other than paying publishers for content. These are organisations with which UKRI could forge relationships in order to support its OA strategy.

Q55. Are there any technical standards that UKRI should consider requiring and/or encouraging in its OA policy to facilitate access, discoverability and reuse of $O A$ monographs, book chapters and edited collections?

Yes / No / Don't know / No opinion.

Please expand (2,000 characters maximum, approximately 300 words).

UKRI should be wary of requiring platforms and repositories to meet particular stringent technical standards for access and discovery, as there is a risk in doing so of preventing disruptive innovation and experimentation. Furthermore, stringent technical requirements tend to benefit established commercial presses that have the finances to develop their platforms. Any technical standards should be accompanied by funding to help presses develop these to meet these requirements (in a similar way to OpenAIRE).

Q56. Do you have any other suggestions regarding UKRl's proposed OA policy and/or supporting actions to facilitate access, discoverability and reuse of $O A$ monographs, book chapters and edited collections?

Yes / No / Don't know / No opinion.

If yes, please expand (2,000 characters maximum, approximately 300 words).

This is an opportune moment to explore what new forms of reading and engagement with books have emerged under the influence of open access and digitisation. As Jisc's landscape study of new university presses (NUPs) and academic-led presses (ALPs) (Adema \& Stone 2017) identified, publishers and authors want to publish multimodal and experimental work, but currently lack the finances and/or technological skills. Similarly, although technological opportunities to enable reuse of and engagement with OA books are on the rise, the actual amount of interaction (e.g. commenting, post-publication peer review) with OA books is still limited. Supporting the creation of, interaction with and reuse of OA books in all their variety and complexity (including emergent and experimental genres) is crucial. This can be achieved most importantly by promoting licenses that allow reuse and derivatives, and by ensuring that such complex digital research publications can be archived 
effectively. Certain scholarly fields and communities within the Humanities and Social Sciences are already accustomed to interacting more deeply with open and digital books, whereas among other fields and communities this type of engagement is less widely established. There are clear opportunities here to explore how the new opportunities that are being opened up for researchers in the HSS as a result of new technological innovations and platforms, will allow them to engage more deeply and directly with scholarly research and publications. This includes building communities around content and collections via annotations, comments and post-publication review (e.g. hypothes.is) to enable more collaborative forms of knowledge production. There are opportunities here for funders such as UKRI to encourage this further by both supporting and making authors aware of these kinds of interactive open source platforms and tools, whilst promoting the new forms of engagement they enable.

\section{Section C: Monitoring Compliance}

Q57. Could the manual reporting process currently used for UKRI OA block grants be improved?

Yes / No / Don't know / No opinion.

If yes, please explain how (2,000 characters maximum, approximately 300 words).

Q58. Except for those relating to OA block grant funding assurance, UKRI has in practice not yet applied sanctions for non-compliance with the RCUK Policy on Open Access.

\section{Should UKRI apply further sanctions and/or other measures to address non-compliance with its proposed OA policy?}

Yes / No / Don't know / No opinion.

Please explain your answer (2,000 characters maximum, approximately 300 words).

If there are going to be any sanctions these should be at the level of institutions. We caution against sanctions on individual researchers/projects; there should be support for institutions to ensure they have the necessary systems and processes in place for researchers to be compliant (including as communications plan). Many humanities researchers already associate open access with compliance and sanctions. UKRI should be sensitive to this association and make sure to highlight the benefits and potential of open access for humanities research. 
Q59. To what extent do you agree or disagree with the example proposed measures to address non-compliance with the proposed UKRI OA policy (see paragraph 119 of the consultation document)?

Strongly agree / Agree / Neither agree nor disagree / Disagree / Strongly disagree / Don't know / No opinion.

Please explain your answer (2,000 characters maximum, approximately 300 words).

We feel the proposed measures to address non-compliance are sufficient.

\section{Section D: Policy Implications and Supporting Actions}

Q60. Do you foresee any benefits for you, your organisation or your community arising from UKRl's proposed OA policy?

Yes / No / Don't know / No opinion.

Please expand (2,650 characters maximum, approximately 400 words).

Yes. Expanding the number of books available in open access would be a great start towards providing wider access and dissemination of knowledge and research in the Humanities and Social Sciences. It will also push publishers to move towards providing open access programmes for books and will hopefully (if the infrastructural investments we propose in the questions above, are made), also enable the rise of more scholar-led, library and university presses, and hence more diversity in the publishing landscape.

More support for community-owned, open infrastructure for $\mathrm{OA}$ publishing will be a benefit for the publishing community as a whole. Projects such as COPIM will support an increase in capacity of OA book publishers, creating a more diverse publishing landscape with greater capacity for equitably funded Open Access.

Q61. Do you foresee UKRl's proposed OA policy causing and/or contributing to any disadvantages or inequalities?

Yes / No / Don't know / No opinion. 


\section{If yes, please expand, referencing specific policy elements and including any comments on} how UKRI could address any issues identified (2,650 characters maximum, approximately 400 words).

There will be disadvantages for $\mathrm{PhD}$ students, para-academics and some ERCs in-between institutions if funding to enable BPC payments is not made available equally to these groups, as they are not eligible to apply for UKRI funding. Green OA remains an option. However, there are issues with licenses for OA books not allowing green OA deposits of post-peer review versions (or only with very long embargoes). Unlike the Sherpa Romeo database, there is no centrally maintained database for publisher policies for self-archiving books or book chapters. It would be very useful if something like this were to be made available for authors.

Q62. Do you foresee any positive and/or negative implications of UKRI's proposed OA policy for the research and innovation and scholarly communication sectors in low-and-middle-income countries?

Yes / No / Don't know / No opinion.

\section{If yes, please expand, referencing specific policy elements and including any comments on how UKRI could address any issues identified (2,650 characters maximum, approximately 400 words).}

Benefits: increased open access to HSS and book research for scholars and the general public.

Drawbacks: If funding is provided for scholars in the UK to publish in OA by paying for BPCs this will create further inequalities in access to publishing for scholars in the so-called Global South (also see Aguado-López and Becerril-Garcia,2020). This is why we are arguing for further investment in open infrastructure for books, and for the promotion of non-BPC business models for OA books.

Also, see our answers above - especially those around the use of a CC BY-NC licence vs a CopyFarLeft licence, for example, and the implications for indigenous communications and local knowledges.

We also caution against framing $\mathrm{OA}$ in terms of mere benefits for low- and middle-income countries, rather than an opportunity to learn from them. It is vital to recognise that countries outside the Global North have much to teach us for their approaches to open access monographs (see the Radical Open Access Collective for examples of this), particularly as many of these are funded by public money. This means that the UKRI policy poses both an opportunity and a threat to low- and middle-income countries in how it could either widen the gap between our approaches to knowledge creation or allow us to learn from their innovation here. We would encourage UKRI to invite Global South monograph 
publishers to discuss how the policy framework can learn from their expertise. (See our answer to Q34 for more.)

Q63. Do you anticipate any barriers or challenges (not identified in previous answers) to you, your organisation or your community practising and/or supporting OA in line with UKRl's proposed policy?

Yes / No / Don't know / No opinion.

If yes, please expand, including any supporting actions you think UKRI could undertake to remove or reduce any barriers identified (2,650 characters maximum, approximately 400 words).

None that have not already been identified in our previous answers.

Q64. Are there any other supporting actions (not identified in previous answers) that you think UKRI could undertake to incentivise OA?

Yes / No / Don't know / No opinion.

If yes, please expand (2,000 characters maximum, approximately 300 words).

Continue to support alternative publishers and infrastructure providers for OA, particularly those that are embedded in the humanities communities you hope to reach. It would be wise for UKRI to stimulate connections between, for example, new OA university presses, library presses and scholarled presses, all of whom tend to work in a more collaborative manner and would benefit from support. There are also many connections that could be explored in this area, particularly through the Latin American publishing community and the North American Library Publishing Coalition. Support here would help stimulate community-led experimentation in OA monographs.

The COPIM members have for years argued for monographs to be made OA. Nonetheless, it is clear to us that any requirement toward this that issues from funding bodies should be backed up with the infrastructural and financial provisions needed for publishers and authors to be actually able to do so. Current BPCs, set mainly by commercial publishers, are too high and too unaffordable for the majority of institutions. Instead, we propose funding bodies invest in open source infrastructure for the production of books, and that this infrastructure is governed and run by the communities involved in academic publishing themselves on a not-for-profit basis. (The latter is the approach that has been adopted with great success in Latin America. There, non-commercial OA repositories, journals and 
infrastructural initiatives such as SciELO, Redalyc and AmeliCA are managed by the scholarly community and supported by public funds as part of the public infrastructure needed for research.)

Alongside this, UKRI should be bold in its requirement for no embargoes on green OA books, in recognition of the fact that traditional publishers are not separate to - or more special than - presses who are purely open access.

Q65. Do you foresee any other implications (not identified in previous answers) for you, your organisation or your community arising from UKRI's proposed OA policy?

Yes / No / Don't know / No opinion.

If yes, please expand (2,000 characters maximum, approximately 300 words).

\section{Section E: Further Comments}

Q66. Do you have any further comments relating to UKRI's proposed OA policy?

Yes / No.

If yes, please expand (2,650 characters maximum, approximately 400 words.)

Here we would like to echo our colleagues from Open Book Publishers and say a little more about the 'scaling small' model, which informs the thinking behind both ScholarLed and COPIM (in which the ScholarLed presses are key partners).

Despite the habitual focus on a small group of large legacy presses, there is huge diversity in the Arts and Humanities publishing landscape. Simon Tanner has noted that, for REF2014, 1,180 publishers were associated with the books submitted to Panel D (Arts and Humanities). Many of these were small and/or specialist presses, with the top ten publishers accounting for less than $50 \%$ of submissions.

We believe the scholarly ecosystem is best served by this diversity among publishers, producing a rich variety of books. The best way to 'scale' what OBP does is therefore not to grow bigger ourselves, but to facilitate OA publishing among multiple presses by developing the systems and infrastructures that will enable other publishers to produce Open Access books without needing to charge authors BPCs. In other words, we would be able to scale capacity while supporting smaller presses and projects, rather than relying on a small number of large organisations that can attempt to set the terms of scholarly publishing. 
'Scaling small' has the potential to build capacity for OA book publishing in a significant way. The five not-for-profit, academic-led Open Access presses of ScholarLed have between us published over 500 books, and expect to publish over 80 new titles in the coming year. Our collection is already the secondlargest on OAPEN (see http://library.oapen.org/browse?type=collection).

We have been contacted by a number of small-to-medium-sized presses and publishing projects who are interested in ScholarLed and COPIM and how our work can help to develop and strengthen their own activities. What would the publishing landscape look like if, rather than 5 presses, ScholarLed was 25,50 , or 100 in number?

For more on 'scaling small', see Janneke Adema's presentation at the OpenAIRE 'Beyond APCs' workshop at the Hague on 5 April 2017, and 'Bibliodiversity in Practice: Developing CommunityOwned, Open Infrastructures to Unleash Open Access Publishing' by Lucy Barnes and Rupert Gatti, ELPUB 2019 23rd edition of the International Conference on Electronic Publishing, Jun 2019, Marseille, France, doi: 10.4000/proceedings.elpub.2019.21.

Q67. Do you have any further comments relating to commonality between UKRI's proposed OA policy for outputs acknowledging UKRI funding and the OA policy for the REF-after-REF 2021?

Yes / No.

If yes, please expand (2,650 characters maximum, approximately 400 words.)

Q68. Do you have any further thoughts and/or case studies on costs and/or benefits of OA?

Yes / No.

If yes, please expand (2,650 characters maximum, approximately 400 words).

Please find a list of fully open access scholar-led book presses that have provided transparent information about their business models and costing structures here:

Barnes, Lucy, and Rupert Gatti. 'The Cost of Open Access Books: A Publisher Writes'. Open Book Publishers Blog, 28 May 2020. https://doi.org/10.11647/OBP.0173.0143.

Eve, Martin, 'How much does it cost to run a small scholarly publisher?' (2017) Martin Paul

Eve https://www.martineve.com/2017/02/13/how-much-does-it-cost-to-run-a-small-scholarly= publisher/ 
Gatti, Rupert, 'Introducing Some Data to the Open Access Debate: OBP's Business Model' (2015) Open Book Publishers Blog https://blogs.openbookpublishers.com/introducing-some-data-to-the-openaccess-debate-obps-business-model-part-one/

Hall, Gary ‘Open Humanities Press: Funding and Organisation’ (2015) Media Gifts http://garyhall.squarespace.com/journal/2015/6/13/open-humanities-press-funding-andorganisation.html

Nordhoff, Sebastian, 'Calculating the costs of a community-driven publisher' (2016) Language Science Press Blog https://userblogs.fu-berlin.de/langsci-press/2016/04/18/calculating-the-costs-of-acommunity-driven-publisher/

Nordhoff, Sebastian, 'What's the cost of an open access book?' (2015) Language Science Press Blog https://userblogs.fu-berlin.de/langsci-press/2015/09/29/whats-the-cost-of-an-open-access-book

Photo by Eli Francis on Unsplash 